\title{
El croquis de la catedral de Mérida, Yucatán, de 1574
}

Víctor Hugo Medina Suárez

UNIVERSIDAD AUTÓNOMA DE YUCATÁN, victor.medina@correo.uady.mx

\section{INTRODUCCIÓN}

\begin{abstract}
n febrero de 2015 se realizó una temporada de trabajo en el Archivo General de la Nación, con la intención de obtener fuentes que sirvieran de puntales para la historia de la Iglesia novohispana en Yucatán. En ese contexto se halló un expediente fechado en 1589 titulado: "Apelación de Gracián de Balzola en nombre de Leonor de Cabrera, con motivo de un fallo adverso en relación con las sepulturas de la catedral de Yucatán”. ${ }^{1}$ Dentro de este legajo se encontró la copia de un croquis de la catedral de Mérida realizado en el año de 1574, en tiempos de la gestión del polémico obispo fray Diego de Landa (1572-1579). ${ }^{2}$

La importancia de este documento es mayúscula pues no sólo se trata de la más antigua imagen del máximo templo yucateco, sino
\end{abstract}

1 "Apelación de Gracián de Balzola en nombre de Leonor de Cabrera, con motivo de un fallo adverso en relación con las sepulturas de la catedral de Yucatán”. AGN, Indiferente virreinal, clero regular y secular, caja 5016, exp. 12, 1589, s/f.

${ }^{2}$ Fray Diego de Landa fue un fraile franciscano que llegó a ser provincial de la orden en Yucatán, para luego ser nombrado obispo en 1572. Llegó a Yucatán en 1549 como misionero y fue testigo protagónico de la expansión de su orden en el proceso evangelizador de los mayas yucatecos. Su política contra la idolatría causó un gran conflicto en Yucatán, pues, realizó violentos actos en contra de los indígenas, resaltando entre sus acciones el auto de fe ejecutado en el pueblo de Maní. Para más información véase Carrillo 1979, tomo 1, 275 ss y Chuchiak 2006, 29 ss. 
que es la representación de la catedral más antigua en tierra firme americana que se mantiene con la mayor parte de su estructura arquitectónica original. El objeto del croquis fue documentar la distribución de las primeras sepulturas y asientos de la catedral, con los nombres de aquellos que adquirieron un espacio en el templo. Así, este documento retrata la primera ocupación que se le dio a ese edificio por la "Iglesia militante" representada en los conquistadores, mientras que proyecta al mismo tiempo la división del subsuelo catedralicio que representa, con las tumbas, a la "Iglesia purgante"; y también materializa la idea de una "Iglesia triunfante" que se podía hallar representada en los altares. Con todo esto, la conclusión del templo y sus ajuares simbolizan la materialización de la cosmovisión cristiana del siglo XVI que se hizo presente en la nueva ciudad con intenciones de posteridad, esto es, la catedral de Mérida era un vehículo de trascendencia espiritual y terrenal para los primeros meridanos.

Todo parece indicar que para la proyección de la distribución de las sepulturas fue necesario utilizar el plano original de la catedral y sobre él asentar el plan funerario de Landa. Decimos esto porque para 1574 -cuando se realizó el croquis- la catedral todavía no cerraba sus bóvedas y es entonces imposible que el templo tuviera un coro, altares, asientos para las autoridades, enverjados y otros elementos que aparecen en el plano. Así, el documento que nos ocupa se podría considerar como la única copia - hasta ahora- del proyecto original de la catedral yucateca, que muy posiblemente tuvo en sus manos el primer obispo de Yucatán fray Francisco de Toral (15611571) cuando puso la primera piedra del templo.

Con todo esto, el croquis de 1574 se convierte en una ventana para mirar a esta catedral, tal como se pensó al menos desde tiempos del episcopado de fray Diego de Landa (1572-1579), a los 32 años de la fundación de Mérida. ${ }^{3}$ El documento refleja el utillaje mental de los primeros colonizadores que hicieron con sus sepulturas un proyecto para sus muertes, pero que con ellas, paradójicamente, activaron la vida de su catedral que comenzaba a forjarse como el eje

${ }^{3}$ Mérida fue fundada por Francisco de Montejo, el Mozo, el 6 de enero de 1542. 
rector de la evangelización y que dio inicio al complicado proceso secularizador en detrimento de la poderosa orden franciscana que antes de la llegada del primer obispo residente mantenía un poder hegemónico.

El comportamiento religioso de los primeros españoles llegados a América sin duda responde a la religiosidad europea barroca del siglo Xvi, culmen de la Baja Edad Media. Como bien apunta Fernando Martínez Gil, la sociedad española del siglo xvi era "una sociedad de privilegios y no de derechos, una sociedad en que la desigualdad no era sólo un hecho real, sino que además estaba refrendada jurídicamente". ${ }^{4}$ Esta idea se refleja en el croquis de 1574, pues, las sepulturas ahí registradas representan a la elite de la estructura social americana que buscaba reconocimiento y trascendencia. El tomar los espacios de la catedral se suma al interés de los colonos que, al igual que en la península ibérica, buscaban el control de las ciudades a través de la municipalidad, la cual recayó en manos de oligarquías muy cerradas y unas pocas familias monopolizaron los cargos de manera vitalicia y en muchas ocasiones de forma hereditaria. ${ }^{5}$ Este grupo de familias privilegiadas controlaba todo: la economía, la política, la milicia e incluso la Iglesia, pues, miembros de estas familias dominaron muchos beneficios eclesiásticos. A todo esto hay que añadir el tema agrario, pues, en la España del siglo XVI la tierra era un medio eficaz para hacer riquezas e incluso ennoblecerse y existía cierta flexibilidad en el entramado social, pues, si bien es cierto que perduró el orden estamental, también es verdad que existió un tipo de movilidad social que permitió ascensos vinculados con las riquezas logradas con el trabajo. ${ }^{6}$ Así, si bien la encomienda satisfacía las necesidades señoriales de los colonos, también la adquisición de tierras y la consecuente fundación de estancias ganaderas, luego las haciendas permitieron la obtención de riqueza y prestigio en mayor o menor grado. De esta manera, el escenario social que se vislumbra para las ciudades de la península ibérica del siglo XVI se reprodujo en las ciudades que se fundaron en América. Los españo-

${ }^{4}$ Martínez 1993, 92.

${ }^{5}$ Martínez 1993, 92.

${ }^{6}$ Martínez 1993, 91. 
les que llegaron al Nuevo Mundo trasladaron sus intereses, sus saberes, sus creencias, sus virtudes, sus vicios... y con todos ellos fundaron sus asentamientos, sus urbs con sus edificios icónicos, entre ellos, la catedral, para ser apropiados por los civis, o los ciudadanos que le dieron un valor simbólico y utilitario a la infraestructura que erigieron.

Así, el croquis de 1574 se convierte en una importante fuente para entender a la primera sociedad hispano nueva. La catedral, mucho más que un espacio de culto, es un santuario de representaciones colectivas materializadas y codificadas, que reflejan las mentalidades de la época, sobre todo, para aquella sociedad que marcaba pocas fronteras entre lo espiritual y lo terrenal. Sus pinturas, imágenes, retablos, vasos sagrados, lápidas, escudos de armas, decoraciones arquitectónicas, campanas, capillas y, en general, todos los elementos que la conformaban, fueron objetos intencionados que pretendían generar una reacción o comportamiento en el espectador o en el usuario. Ningún elemento fue inocente, nada fue propio de la casualidad, todo fue pensado por alguien para destinatarios concretos, buscando incidir en las conductas.

El croquis de 1574 existe gracias a un conflicto entre dos familias españolas avecindadas en Mérida, quienes litigaron por el lugar que creían les pertenecía dentro de la catedral. Se trata entonces de dos familias que entre sus utillajes mentales traían la conciencia de ser miembros privilegiados de la sociedad, con derecho a ocupar un lugar especial dentro del templo, con méritos que les permitían exigir prerrogativas reales, con una marcada religiosidad barroca que se refleja en las costumbres funerarias y que se hallaron en pugna por el control político de la joven ciudad que se había fundado en 1542 por Francisco de Montejo, el Mozo.

\section{El CONTEXTO DEL DOCUMENTO}

La existencia del croquis se debe al litigio que procuró Leonor de Cabrera contra doña Guiomar de Acevedo. La primera fue esposa del conquistador Hernando de Bracamonte y la segunda fue consorte del famoso doctor don Diego de Quijada, alcalde mayor de 
Yucatán; esto es, se trata de un conflicto entre una familia conquistadora y fundadora, allegada a los Montejo, ${ }^{7}$ contra la nueva elite política considerada por los pioneros como advenediza y sin méritos de conquista.

Hernando de Bracamonte fue un caballero hidalgo originario de Medina del Campo, que pasó a las Indias en compañía de Jerónimo de Artal, quien había sido gobernador del Río de Marañón en el Perú y participó en las expediciones que dieron como resultado el descubrimiento de varias poblaciones asociadas al ya nombrado río. En estos malogrados viajes murieron muchos españoles y por esto Bracamonte decidió abandonar temporalmente el proyecto. Persistente con la idea de lograr gloria y riquezas, Bracamonte pasó a Puerto Rico desde donde se organizaban expediciones para regresar al Perú y se enlistó en una de éstas junto con Antonio de Sedeño. No obstante, sus intentos fueron infructuosos, pues, las expediciones fueron un fracaso, por lo que decidió pasar a Yucatán, junto con su hermano Francisco, buscando nuevas suertes. Bracamonte participó con Francisco de Montejo, el Mozo, en la conquista y pacificación de Yucatán, fue uno de los fundadores de Mérida y peleó contra los indios en las constantes sublevaciones. Una vez que se estabilizó el orden hispano en Yucatán, Hernando de Bracamonte fue teniente de gobernador, alcalde ordinario y regidor de la ciudad de Mérida. ${ }^{8}$ Su esposa, Leonor de Cabrera, era originaria de la ciudad de México, hija de Pedro Álvarez de Castańeda y de Beatriz de Cabrera. ${ }^{9}$ Diego López de Cogolludo enlista a Álvarez de Castañeda como uno de los primeros vecinos de la ciudad de Mérida en el momento

${ }^{7}$ Nos referimos a Francisco de Montejo, el Viejo, adelantado de Yucatán y a su hijo Francisco de Montejo, el Mozo, quien llevó a cabo la conquista de Yucatán y fundación de la ciudad de Mérida. A éstos debe añadirse Francisco de Montejo, sobrino del adelantado, quien conquistó la región en donde se fundó la villa de Valladolid. Los tres Montejo fueron los que controlaron a la entonces joven provincia hasta el juicio de residencia del adelantado (1550), por el cual perdieron todos los privilegios que habían logrado en las capitulaciones negociadas ante Carlos I de España en 1526.

${ }^{8}$ Méritos y servicios: Hernando de Bracamonte: río Marañón, etc. AGI, Patronato, 83, N.4, R.4,

${ }^{9}$ Rubio 1943, 18. 
de su fundación, ${ }^{10}$ por lo que es de suponer que este hombre fijó su residencia en Yucatán desde 1542, trayendo con él a su esposa e hijas, entre ellas estaba dońa Leonor. No se sabe con certeza cuándo ocurrió el matrimonio de Hernando de Bracamonte con Leonor de Cabrera, sin embargo, es muy probable que la unión se haya realizado en Mérida a mediar el siglo XvI, pues su primer hijo se registró en el libro primero de bautizos de la ciudad, en octubre de $1554 .{ }^{11}$ Así, el matrimonio Bracamonte-Cabrera, quedó inserto entre las primeras familias conquistadoras, fundadoras de una ciudad que se erigió sobre las ruinas de la civilización dominada; ambos fueron testigos del primer trazo reticular a cordel, de la puesta de las primeras piedras de los edificios; vivieron los miedos de los constantes ataques de los mayas y se enfrentaron a ellos; apostaron dejar todo por establecerse en aquel lugar para comenzar una nueva vida, una nueva historia. Todo esto fue lo que alegaron por sus méritos, constantemente recordaban sus hazañas pioneras y, por todo lo dicho, sentían que tenían derechos superiores sobre todos los que fueron llegando después.

Por otro lado, el doctor Diego Quijada fue un universitario salmantino que construyó su carrera política en Indias sirviendo primero en Guatemala como fiscal de la Audiencia de los Confines, para luego ser nombrado visitador y alcalde mayor de Nicaragua. Durante la década de 1550 vivió en San Salvador, siendo incluso encomendero. En 1560 fue nombrado por Felipe II alcalde mayor de Yucatán y Tabasco y llegó a Mérida en junio de 1562. Su esposa, doña Guiomar, se reunió con Quijada en Mérida meses después. ${ }^{12}$ Diego de Quijada puede considerarse como uno de los primeros españoles que pasaron a las Indias. France V. Scholes piensa que Quijada estableció su residencia en Guatemala probablemente en $1544^{13}$ fecha temprana en los procesos de conquista americanos. No obstante, Quijada no participó en las reyertas militares contra los

${ }^{10}$ López de Cogolludo 1688, 166.

11 "Acta de bautizo de Juan, hijo de Fernando de Bracamonte y Leonor de Cabrera, 1 de octubre de 1554" APAY, Bautizos, vol. 1, 1543-1633.

${ }^{12}$ Para todos los datos relativos a Quijada véase Scholes 1938, xxvı y XXvII.

${ }^{13}$ Scholes 1938, xxvI. 
indígenas, no se enlistó en las expediciones que abrían brecha para la fundación de las primeras ciudades y villas y, por lo tanto, no tuvo los méritos de los que presumían familias como los Montejo y los Bracamonte. Peor aún, las acciones políticas de Quijada fueron consideradas por los pioneros como atentados a sus privilegios y derechos ganados por sus méritos de conquista.

En tiempos de Quijada, el principal conflicto que inquietó a toda la sociedad fue la concesión de las encomiendas a advenedizos y la prohibición del uso de la mano de obra indígena como servicio personal. Yucatán, carente de recursos y productos comerciables en los mercados, volcó su modo de enriquecerse en la encomienda y en el trabajo forzoso de los indios. Los primeros conquistadores, beneficiados con aquellos sistemas, lucharon en conjunto contra todo aquel que pretendiera modificar el statu quo que les brindaba recursos y satisfacía sus pretensiones señoriales. ${ }^{14}$ Por lo mismo, los encomenderos de Mérida arremetieron contra Diego Quijada, quien desde los primeros meses de su llegada trató de desarticular la concesión dada a los encomenderos "para emplear a los indios de sus encomiendas como criados para el servicio de sus casas". ${ }^{15} \mathrm{El}$ conflicto se intensificó cuando el doctor Quijada otorgó la encomienda de Yaxcabá -que recién había quedado vacante-, "a cierto Juan Díaz que le había acompañado de España el ańo anterior y que había establecido su casa en Valladolid [Yucatán]". ${ }^{16}$ Los encomenderos mostraron mucho resentimiento al enterarse de que la encomienda fue entregada a un advenedizo, sin méritos, y amigo del alcalde mayor y más se enfurecieron cuando Quijada hizo cumplir la legislación sobre casamiento de encomenderos, lo que los obligaba a contraer matrimonio para poblar la tierra y así poder gozar de los beneficios. ${ }^{17} \mathrm{El}$ alcalde mayor trató de aplicar muchos otros cambios que desfavorecían a los encomenderos, pero al final perdió la partida, pues, cometió excesos que fueron evidenciados, sobre todo, en el polémico asunto en el trato dado a los indios en los procesos contra

${ }^{14}$ Véase García 2005, 261.

${ }^{15}$ Scholes 1938, XXviI.

${ }^{16}$ Scholes 1938, xxxi.

${ }^{17}$ Scholes 1938, xxxII. 
las idolatrías que llevaron a cabo los franciscanos encabezados por Diego de Landa. El Consejo de Indias halló culpable al alcalde mayor y, tratando de defenderse, hizo viaje a España en donde murió. ${ }^{18}$ Lo que aquí se debe resaltar es el enfrentamiento que hubo entre el grupo del alcalde mayor y los pioneros residentes de la provincia, pues, el conflicto entre Leonor de Cabrera y Guiomar de Acevedo, motivo de este estudio, es un claro reflejo de esta situación.

El problema entre estas dos mujeres de la primera elite meridana comenzó el 20 de septiembre de 1588, cuando el obispo Gregorio de Montalvo (1580-1587), sucesor de Landa, otorgó a Guiomar de Acevedo un asiento en la catedral, frente al altar de San Cristóbal, que en aquel entonces se hallaba coronando la nave sur del templo. Esta acción contravenía el plan funerario original de fray Diego de Landa, pues, el asiento dado a doña Guiomar quedó delante del de la familia Bracamonte cuando, originalmente, esta familia se hallaba en primera fila, frente al mencionado altar. Como se apunta en los alegatos del pleito, Leonor de Cabrera y su familia se sintieron defraudados en su honor y preeminencia ${ }^{19}$ que se había reconocido en tiempos del obispo Landa, al haber sido considerados para ocupar un lugar especial dentro del templo.

El derecho a tener asiento y sepultura en una iglesia y mucho más en una catedral, era una práctica propia de las elites españolas. El lugar que una persona ocupaba en los actos litúrgicos, tanto en la vida como en la muerte, denotaba su rango en la sociedad y era una manera de separarse del vulgo, pues, el espacio de asiento era exclusivo para la familia que participaba en el culto, sobre las lápidas que marcaban la última morada de sus familiares. De hecho, el asiento y sepultura solía estar señalado por un marco de madera, con el objeto de dejar en claro a los demás cuál era el espacio exclusivo de tal o cual familia. Siguiendo esa costumbre, doña Guiomar de Acevedo, segura de haber obtenido la venia del obispo Montalvo, puso su marco de madera y en ese espacio se sentaba para participar en la

${ }^{18}$ Scholes 1938, xCviII ss.

19 "Apelación de Gracián de Balzola en nombre de Leonor de Cabrera, con motivo de un fallo adverso en relación con las sepulturas de la catedral de Yucatán”. AGN, Indiferente virreinal, clero regular y secular, caja 5016, exp. 12, 1589, f. 45. 
misa,${ }^{20}$ hecho que Leonor de Cabrera consideró un gran atentado a su posición social. Hay que mencionar que este tipo de problemas no fueron exclusivos del caso que nos ocupa. Existe evidencia documental de muchos pleitos semejantes ocurridos en Espańa, como el juicio litigado en Cizúrquil (Guipúzcoa) por Antonio Pegamuño contra Juan de San Millán, cuando el segundo mandó a quitar los marcos de madera de la sepultura del primero, ${ }^{21}$ entre muchos otros que se pueden ver en los archivos españoles y que se asemejan al caso de Leonor de Cabrera y Guiomar de Acevedo.

En realidad, el conflicto que aquí se trata es "la punta de un iceberg", que pudiera parecer tan sólo un pleito parroquiano de una sociedad cuasimedieval necesitada de las parafernalias. Pero no, Leonor de Cabrera se enfrentó a Guiomar de Acevedo por lo que cada una representaba. El problema de la sepultura fue sólo un punto en el que confluyó un profundo conflicto político y social entre el grupo de los encomenderos y la nueva elite política, fomentada por la Corona, para lograr el control de sus tierras en ultramar y así restarle poder a los conquistadores, quienes se sentían dueños y señores de sus colonizaciones, estorbando los intereses reales del momento. Esta nueva elite responde a la estrategia de la Corona por crear un aparato burocrático "dotado de ministros y funcionarios, muchos de ellos, aunque no todos, letrados con formación universitaria", ${ }^{22} \mathrm{y}$ entre este grupo de burócratas se hallaban el doctor Quijada y su mujer. La situación nos recuerda una de las ideas del historiador hispanista John $\mathrm{H}$. Elliott, quien propone que la sociedad indiana del siglo Xvi "vivía en un permanente estado de expectativa: la expectativa, demasiado a menudo defraudada, de que la lealtad recibi-

20 "Apelación de Gracián de Balzola en nombre de Leonor de Cabrera, con motivo de un fallo adverso en relación con las sepulturas de la catedral de Yucatán”. AGN, Indiferente virreinal, clero regular y secular, caja 5016, exp. 12, 1589, f. 3 .

21 "Ejecutoria del pleito litigado por Antonio de Pagamuño, Juan de Luzuriaga y Juan de Mecola, vecinos de la tierra de Cizúrquil (Guipúzcoa), señores de sus respectivas casas, con Juan de San Millán, de la misma vecindad, sobre amparo a los primeros en su derecho a tener asiento y sepultura en la parroquia de San Millán de Cizúrquil (Guipúzcoa), y reposición de los marcos y tablas de madera que Juan de San Millán retiró de dichas sepulturas.” Archivo de la Real Chancilleria de Valladolid, Registro de ejecutorias, caja 1451, 18.

${ }^{22}$ Elliott 2010, 235. 
ría la recompensa merecida”. ${ }^{23}$ Esta expectativa que nos sugiere Elliott es muy clara en la familia Bracamonte y mucho más en Leonor de Cabrera que además era criolla. Es muy conocida la pugna entre los españoles americanos (criollos) y los "gachupines". Severo Martínez Peláez, en su estudio sobre los criollos guatemaltecos y recurriendo a la obra de Francisco Antonio de Fuentes y Guzmán, Recordación Florida, propone la existencia de "dos Españas” en la mentalidad de la época: "una, la España conquistadora [...] llena de hidalguía y de elevadas miras, [y] otra, la España mezquina, representada por funcionarios de espíritu calculador y por barcadas de emigrantes que ambicionaban una tajada del Nuevo Mundo". ${ }^{24} \mathrm{El}$ lío del asiento y sepultura de los Bracamonte responde exactamente a ese conflicto que Martínez Peláez estudió para Guatemala.

En una visión más amplia, el pleito por los asientos y sepulturas de la catedral nos permite entender al concepto de monarquía que puede ser vista "como un vasto complejo de grupos de presión e intereses, todos en rivalidad entre sí por la atención y el favor del monarca" ${ }^{25}$ Tener un asiento y sepultura en la primera fila, frente al altar de San Cristóbal, en el nuevo templo de la joven ciudad, iba más allá de la religiosidad. Se trataba más bien de un símbolo social y político codificado, en primer lugar, para todos los habitantes de Mérida y en segundo para todo español. El código no es muy difícil de descifrar: los Bracamonte-Cabrera pretendían ser una familia de primera fila, exigente con su señor terrenal por la fidelidad y servicios que presumían, muy espańoles, pero que ya manifestaban la sensación de la diferencia: comenzaban a sentirse de segunda clase, se estaban americanizando, estaban construyendo la identidad criolla que siglos más tarde procuró la Independencia.

En 1589, cuando aconteció el pleito, Mérida era una joven ciudad con apenas 47 ańos de haberse fundado. La catedral ya estaba en funciones, pues, en la documentación se acusa a Guiomar de Acevedo que desde 1588 ya tenía asiento desde donde escuchaba misa. La evidencia la tenemos en las declaraciones de Leonor de Cabrera:

${ }^{23}$ Elliott 2010, 231.

${ }^{24}$ Martínez 2012, 45.

${ }^{25}$ Elliott 2010, 237. 
y estando en quieta e pacífica posesión del asiento y entierro de la dicha sepultura, sin contradicción de persona alguna todo el dicho tiempo, la dicha dońa Guiomar de Acevedo se entró en parte de ella a los 25 días del mes de octubre del año próximo pasado de quinientos ochenta e ocho y contra el dicho mi derecho de propiedad e posesión, se sentó en la dicha mi sepultura, en la parte de arriba de ella, que llega a la peana del altar de San Cristóbal, en tiempo que yo no estaba en la Iglesia, y dio su marco de madera y ha ido continuando de sentarse en el mismo lugar y hasta algunas las veces que va a misa a la dicha santa Iglesia. ${ }^{26}$

Estos datos otorgan mayor precisión para el primer momento en que la catedral ya estaba en uso. Bretos menciona que "la catedral estaba en condiciones de ser utilizada en algún momento entre 1598 y $1603 " .{ }^{27}$ No dudamos, como bien apunta Bretos, que el primer uso solemne del templo haya sido "para la jura y alza de pendones por Felipe III el 18 y 19 de abril de 1599 ", ${ }^{28}$ pero por la documentación hallada tenemos certeza de que en la catedral se decía misa desde al menos 1588 cuando Leonor de Cabrera entró en conflicto con Guiomar de Acevedo. Para entonces, aquella primera iglesia de paja proclive al incendio, tan mencionada en la documentación, ya estaba en desuso. En el nuevo y magnífico templo ya resonaba el Kyrie Eleison y su acompañamiento musical de trompetas y chirimías arrullaba la cuna del criollismo.

\section{El POTENCIAL DEL CROQUIS COMO FUENTE}

para la historia. Algunos temas

El documento que nos ocupa tiene gran potencial para los estudios históricos. En este apartado presentaré algunas posibilidades, que estoy realizando y que pronto saldrán como publicaciones. En primer lugar, el croquis presenta la información de aquellos individuos

26 "Apelación de Gracián de Balzola en nombre de Leonor de Cabrera, con motivo de un fallo adverso en relación con las sepulturas de la catedral de Yucatán". AGN, Indiferente virreinal, clero regular y secular, caja 5016, exp. 12, 1589, f. 3 .

${ }^{27}$ Bretos 2013, 89.

${ }^{28}$ Bretos 2013, 89. 
que adquirieron una sepultura y asiento en la catedral. Es importante señalar que sólo se tienen los nombres de los que adquirieron la tumba en vida, lo que no quiere decir que necesariamente hayan sido enterrados en aquel sitio, sin embargo, ante la importancia que implica una catedral, lo más probable es que su última morada haya sido en el espacio que obtuvieron. Las personas que adquirieron una sepultura en 1574 se muestran en el cuadro 1.

Cuadro i. Personas que adquirieron una sepultura en 1574

\begin{tabular}{|c|c|c|}
\hline Nave norte & Nave central & Nave sur \\
\hline Andrea del Castillo & $\begin{array}{l}\text { Fernando de Castro } \\
\text { Polanco }\end{array}$ & La de Castañeda \\
\hline Antonio de Mayorga & Melchor Pacheco & Hernando de Bracamonte \\
\hline Diego Álvarez & Joan de Magaña Arroyo & Francisco de Magaña \\
\hline Joana Suárez & Marcos Rodríguez & Luis de Santa Cruz \\
\hline \multirow[t]{16}{*}{ Rodrigo Franquez } & Francisco Tamayo & Cristóbal Sánchez \\
\hline & Francisco Pacheco & Alonso de Castro \\
\hline & Jerónimo de Castro & Lucas de Paredes \\
\hline & Nuño de Castro & Gómez de Castrillo \\
\hline & & Cristóbal de San Martín \\
\hline & & Francisco de Arceo \\
\hline & & Cristóbal de Rojas \\
\hline & & Ana de Campos \\
\hline & & Joan López \\
\hline & & Nicolás de Aquino \\
\hline & & Blas Hernández \\
\hline & & Bartolomé Rojo \\
\hline & & Joan Bote \\
\hline & & Jerónimo Pérez \\
\hline & & $\begin{array}{l}\text { Beatriz López, la viuda de } \\
\text { Antón Julián }\end{array}$ \\
\hline & & Diego Hernández de Hoyos \\
\hline
\end{tabular}

Fuente: "Apelación de Gracián de Balzola en nombre de Leonor de Cabrera, con motivo de un fallo adverso en relación con las sepulturas de la catedral de Yucatán”. AGN, Indiferente virreinal, clero regular y secular, caja 5016, exp. 12, 1589, f. 3 . 
Alrededor de la capilla mayor y en la nave central, se proyectaron treinta sepulcros, de los cuales sólo se concedieron siete en 1574. Voy a referirme sólo a algunos de los nombres que se encuentran en el croquis para hacer notar la importancia de los individuos que adquirieron su sepultura, dejando para otro trabajo el estudio prosopográfico. Entre estos nombres resalta el de Fernando de Castro Polanco, escribano mayor de la gobernación, ${ }^{29}$ capitán de caballos, reconocido defensor de la Habana ante los ataques de los ingleses, alférez mayor, maestro de campo de toda la provincia en $1596^{30} \mathrm{y}$ teniente de gobernador en 1597. Castro Polanco fue considerado uno de los hombres más ricos de Yucatán al finalizar el siglo $\mathrm{xvI}^{31} \mathrm{y}$ en el croquis aparece su nombre junto con las abreviaturas fr. $d$. eps. Estas letras responden a la frase latina frater didacus episcopus que traducida significa fray Diego obispo, esto es, se trata de la firma episcopal de fray Diego de Landa. Es muy posible que Fernando de Castro Polanco recibiera su sepultura y asiento por parte de este mitrado, por lo que suponemos que era su familiar ${ }^{32}$ o protegido, pues, sólo él y Antonio de Mayorga -de quien hablaremos más adelante- llevan esa frase latina en el croquis y ambos están bien posicionados en la distribución de las sepulturas.

Otro de los nombres es el de Juan de Magańa Arroyo, hijo de Juan de Magaña, ${ }^{33}$ quien fuera conquistador, regidor perpetuo, ${ }^{34}$ contador de la real hacienda, teniente general de la provincia y encomendero. ${ }^{35}$ Magaña Arroyo, aunque también encomendero, ${ }^{36}$ era en realidad heredero de las glorias de su padre y por eso recibió el reconocimiento de tener una sepultura cerca del altar mayor. Hay que recordar que los descendientes de los conquistadores argumen-

${ }^{29}$ Confirmación de oficio: Fernando de Castro Polanco. AgI, México, 172, N. 3

${ }^{30}$ Méritos: Micaela Rodríguez de Villamil y Vargas. AGI, Indiferente, 139, N. 135.

${ }^{31}$ Cartas de gobernadores. AGI, México, 359, R. 8, N. 34.

${ }^{32}$ Los familiares de los obispos no eran necesariamente parientes. Se trataba más bien de personalidades que lo acompańaban, con las cuales el prelado se apoyaba como sus personas de mayor confianza.

${ }^{33}$ Méritos y servicios: Juan de Magaña: Nueva España. Agr, Patronato, 66a , N. 1, R. 6.

${ }^{34}$ Nombramiento de regidor. AGI, Patronato, 293, N. 20, R. 46.

${ }^{35}$ Méritos y servicios: Juan de Magaña: Nueva España. Agı, Patronato, 76, N. 1, R. 10.

${ }^{36}$ Relaciones histórico geográficas..., tomo 1, 2008, 389. 
taron derechos sobre los méritos de sus ascendientes y con esto lograron algunos privilegios por parte de la Corona y de las autoridades virreinales tanto civiles como eclesiásticas.

Toca ahora el turno a Melchor Pacheco, quien también obtuvo su sepultura del lado izquierdo de la capilla mayor. ${ }^{37}$ Los Pacheco que llegaron a Yucatán con Montejo, el Mozo; fueron dos hermanos llamados Gaspar y Melchor y este último llevó el sobrenombre del Viejo para diferenciarlo de su descendencia homónima. Gaspar, ${ }^{38}$ quien fuera el primer alcalde de Mérida y capitán general de la conquista, tuvo un hijo a quien llamó Melchor. Este último fue padre de Melchor Pacheco, quien obtuvo la sepultura en $1574 .{ }^{39}$ En la misma posición que la sepultura que tratamos, pero del lado derecho, se encuentra la tumba de Francisco Pacheco, hijo de Alonso Pacheco y Monroy y nieto de Melchor Pacheco, el Viejo. Así, las dos descendencias de los pioneros hermanos Pacheco quedaron con asientos y sepulturas que franqueaban la capilla mayor de la catedral. Para Ignacio Rubio Mañé, los Pacheco eran la segunda familia de importancia en Yucatán, después de los Montejo. ${ }^{40}$ Esto lo consideró reconociendo los títulos de hidalguía de los que gozó esta familia, ${ }^{41}$ a los que se ańaden sus méritos militares y políticos. Los Pacheco fueron los que llevaron a cabo la conquista del oriente de Yucatán y fundaron la villa de Bacalar, ${ }^{42}$ por lo que gozaron de mucho prestigio en la provincia.

Pasando al lado derecho de la capilla mayor, además de la sepultura de Francisco Pacheco, tenemos las que obtuvieron Francisco Tamayo y la de Jerónimo de Castro. Suponemos que Francisco de Tamayo Pacheco, el Viejo, fue quien adquirió la sepultura en 1574 y no debe confundirse con su hijo que llevó el mismo nombre. Esta suposición la basamos en que en 1586, el Viejo Tamayo seguía vivo, ${ }^{43}$ por lo que como pater familias debió tramitar la sepultura y

\footnotetext{
${ }^{37}$ La tumba se hallaba, viendo el espectador hacia el altar, del lado izquierdo.

${ }^{38}$ Informaciones: Melchor Pacheco. AGI, México, 222, N. 33.

${ }^{39}$ Rubio 1943, 16 y 17.

${ }^{40}$ Rubio 1943,16 y 17.

${ }^{41}$ Méritos y servicios: Melchor Pacheco: Nueva España. AgI, Patronato, 67, R.3.

${ }^{42}$ Ancona, 1978, tomo 1, 344.

43 "Acta de bautizo de Diego de Solís, 1586" APAY, Sagrario, Bautismos, vol. 1, 1543 -
} 
asiento en 1574 , que sería para toda su prole. Francisco de Tamayo fue uno de los primeros conquistadores y fundadores de la ciudad de Mérida junto con Francisco de Montejo, el Mozo, destacando en su labor militar, siendo incluso considerado un héroe por haber socorrido y salvado a muchos españoles durante la sublevación indígena de 1546 en la villa de Valladolid. ${ }^{44}$ También incursionó para tratar de conquistar a los indios del Lacandón, persiguió corsarios ingleses, fue regidor, alcalde y teniente general. ${ }^{45}$

Por último, tenemos la sepultura de Jerónimo de Castro. De este hombre sólo sabemos que fue notario y escribano real desde 1565 hasta los últimos ańos del siglo XvI, ${ }^{46} \mathrm{y}$ pensamos que este oficio le permitió vincularse con la elite de la ciudad, razón por la cual ocupó ese importante lugar dentro del templo.

Pasamos ahora a la nave del mediodía o del sur. Ésta concentra, de acuerdo al croquis, el mayor número de sepulturas elegidas $\mathrm{u}$ otorgadas a los primeros conquistadores. En aquella nave se programaron treinta y dos espacios mortuorios y de éstos, veinte fueron adquiridos en 1574 cuando se realizó el croquis, prefiriéndose aquellas sepulturas que se hallaban adosadas a la pared sur. Entre estas tumbas, ocupando la primera fila, se encuentra la de Hernando de Bracamonte y la de Pedro Álvarez de Castañeda, de quienes ya hemos hablado. Casi todos los demás individuos que aparecen en este lado, tienen la característica de ser encomenderos y muchos de ellos conquistadores como el caso de Alonso de Castro, ${ }^{47}$ Lucas de Paredes ${ }^{48}$ Gómez de Castrillo, ${ }^{49}$ Cristóbal de San Martín ${ }^{50}$ y Fran-

1633, f. 64. En dicha acta aparecen como padrinos don Francisco de Tamayo y su esposa Ana de Arellano.

${ }^{44}$ Molina 1943, tomo II, 331.

${ }^{45}$ Méritos y servicios: Francisco Tamayo Pacheco: Yucatán. AGI, Patronato, 82, N. 2, R. 1.

${ }^{46}$ Véase "Nombramiento de escribano público y de cabildo" AgI, Patronato, 293, N. 20, R. 34 y "Real Provisión de notaría de Indias para Jerónimo de Castro, vecino de la ciudad de Mérida de Yucatán" agI, INDIFERENTE, 425, L. 24, F. $213 \mathrm{~V}$.

${ }^{47}$ Méritos y servicios: Alonso de Castro: Yucatán. AGI, Patronato, 68, N. 2, R. 2.

${ }^{48}$ Méritos y servicios: Lucas de Paredes: Yucatán. AGI, Patronato, 73, N. 1, R. 8.

${ }^{49}$ Consulta del Consejo de Indias. AGI, Indiferente, 741, N. 218.

${ }^{50}$ Real Cédula a los alcaldes del crimen de la Audiencia y Chancillería de Granada para que envíen relación sobre lo que sepan del caso de Cristóbal de San Martín, residen- 
cisco de Arceo. ${ }^{51}$ Hay que mencionar que por el lado sur de la catedral se proyectó el primer sagrario del templo y es posible que por esa razón se hubiese preferido la nave sur para la mayoría de las sepulturas, pues, esto implicaba estar cerca del lugar en donde se resguardaba el santísimo sacramento. Además, la nave sur se coronaba con el altar de San Cristóbal, quien es patrono de los "arqueros y de otros oficios peligrosos" ${ }^{52}$ También se le tiene como protector ante la muerte súbita, es patrón de los descargadores, portadores, barqueros, constructores de barcos, pero, sobre todo, de los viajeros. ${ }^{53}$ Así, los atributos protectores de San Cristóbal iban muy ad hoc con las necesidades y características de aquella sociedad en la que todos eran viajeros, se relacionaban con barcos, eran comerciantes y estaban en constante riesgo de muerte ante las posibles sublevaciones de los indios.

Por último tenemos a la nave norte. En ella resalta, sobre todo, el nombre de Andrea del Castillo, quien fuera la esposa del conquistador Francisco de Montejo, el Mozo. Esta sepultura se suma a un viejo debate sobre la última morada del conquistador, la cual se ha considerado que se encontraba en el convento provincial franciscano que se ubicaba en la zona que hoy ocupa el mercado de San Benito en la ciudad de Mérida, pero que se perdió con la destrucción de ese complejo arquitectónico. Montejo, el Mozo, murió en 1565, antes de que la catedral se concluyera y por eso fue enterrado en el convento franciscano. Justo Sierra O'Reilly menciona que "sus restos fueron depositados en la capilla mayor de San Francisco por no haberse concluido la catedral, en donde se colocaron más adelante aunque ya no parece el sitio". ${ }^{54}$ Los historiadores que han trabajado este tema han descartado la posibilidad de que los restos del conquistador hayan sido trasladados a la catedral, como asegura Sierra, pero el croquis viene a abrir de nuevo la discusión. Un trabajo posterior retomará este asunto y por ahora nos quedamos con una pregunta: ¿por qué

te de Yucatán, huido de galeras, y den un traslado de las sentencias y autos de la ejecución de ellas. AGI, Indiferente, 424, L. 21, F. 185v-186v.

${ }^{51}$ Méritos y Servicios: Francisco de Arceo: Yucatán. AgI, Patronato, 75, N. 1, R. 7

${ }^{52}$ García 2000, 346.

${ }^{53}$ Para todos los atributos y patronazgos de San Cristóbal véase García 2000, 346.

${ }^{54}$ El Fénix. Periódico Politico y Mercantil, Sec. Calendario civil y religioso, núm 20, lunes 5 de febrero de 1849. Campeche. 
la esposa del Mozo compraría una sepultura en la catedral si tenía una cripta familiar en el convento Grande de San Francisco?

Por otro lado, el croquis también nos ofrece la oportunidad de analizar a las primeras devociones que se instauraron en la catedral. En el documento aparecen registrados los tres altares cabeceros del templo. Del más importante o el de la nave central, sólo se apunta con el título de "altar mayor", en donde debió estar la imagen de San Ildefonso, patrono de la catedral, muy posiblemente de lienzo. Esto lo suponemos porque en 1606 el obispo Diego Vázquez de Mercado (1606-1608) le escribió al rey diciéndole que: "para tal iglesia no hay sino una imagen de lienzo puesta en un marco sin otra cosa [...] en seis altares que hay en las naves laterales no hay imágenes ni aderezo para ellas que es una gran falta". ${ }^{55}$

El obispo Diego Vázquez de Mercado le reportó al rey la existencia de sólo una imagen de lienzo, aunque no dice exactamente en dónde se situaba ni a quién representaba. Después menciona la falta de iconos en los seis altares colaterales, esto es, el mitrado hace una diferencia entre el lienzo y la situación de los altares colaterales, lo que nos sugiere que el lienzo en su marco estaba en alguno de los altares principales, muy posiblemente en el altar mayor, pues, como se ve en el croquis, las naves laterales tenían la devoción de Nuestra Señora (nave norte) y la de San Cristóbal (nave sur). El patronazgo de San Ildefonso comenzó en Mérida desde el 23 de enero 1542 cuando Tutul Xiu, importante gobernador maya, se convirtió al cristianismo, ${ }^{56}$ lo que significó para los españoles un gran avance en el proceso de sometimiento de la cultura maya. Ese mismo día se celebraba la fiesta del santo, por lo que se consideró que la rendición, sometimiento y conversión al cristianismo de Tutul Xiu se logró por su intercesión.

Toca ahora el turno al altar de Nuestra Señora ubicado en la nave norte. Hay que empezar recordando que la ciudad de Mérida fue fundada por Francisco de Montejo, el Mozo, "a honor y reverencia de Nuestra Señora de la Encarnación”. ${ }^{57}$ No obstante, como ya se

${ }^{55}$ Documento citado en Bretos 1991, 39.

${ }^{56}$ Cárdenas 1937, 24.

${ }^{57}$ López de Cogolludo 1688, 137. 
dicho, días después de la fundación de Mérida se decidió tomar como santo patrono a San Idelfonso. Sin embargo, el 18 de noviembre del mismo año se reunió el cabildo de la ciudad y decidieron fundar una cofradía con el título de Nuestra Señora de la Encarnación, siendo el mismo Francisco de Montejo, el Mozo, el encargado de promover y cuidar el culto. ${ }^{58}$ Por cierto, la sepultura que adquirió Andrea del Castillo está frente a este altar, hecho que puede ser un indicio que ayude a sustentar el traslado de los restos del Mozo para descansar al pie de su devoción.

Por último, tenemos al altar de San Cristóbal. Ya hemos dicho que esta devoción iba muy acorde a la realidad que vivían los primeros colonos. Todos los conquistadores podían invocar a San Cristóbal porque era una sociedad de militares o al menos milicias que se hallaban en peligro de muerte ante la incertidumbre de la mansedumbre indígena. La devoción temprana a San Cristóbal refleja el miedo ante la muerte que podían sufrir en cualquier momento, que por cierto solía ser una muerte cruel y con tortura lenta cuando caían presos de los naturales rebeldes.

Para terminar, en el croquis también se puede ver el lugar en el que se proyectó el coro de la catedral. Este mueble, hoy desaparecido, era el lugar de los miembros del cabildo catedral, desde donde cantaban la liturgia de las horas y llevaban a cabo sus ceremonias más importantes. Poco sabemos de sus características y no existe ningún estudio sobre este importante espacio. Su proyección en el croquis aporta nuevos datos para abordar su función en el templo y su proyección a la sociedad yucateca con todas las implicaciones religiosas, políticas, sociales y económicas que giraban alrededor de los capitulares.

\section{Conclusión}

Con todo lo mencionado, el croquis de 1574 permitirá reconstruir parte de la jerarquía social de la primera sociedad meridana, a partir de la distribución de las sepulturas y el lugar en el que se hallaron con respecto a los principales o más sagrados lugares del templo. El

${ }^{58}$ López de Cogolludo 1688, 140. 
documento invita al estudio prosopográfico, pero también al análisis particular para revisar la vida de esos individuos y lo que representaban en la comunidad. De los primeros conquistadores yucatecos poco se sabe, y si bien existen estudios aislados, es un gran pendiente historiográfico abordarlos a profundidad y como grupo.

Por otro lado, el análisis de las primeras devociones y del interior del templo también serán un gran aporte. El estudio de las representaciones religiosas explica en gran medida a la sociedad que las generó. Si bien existe hasta hoy el edificio, cosa no menor, sus primeras imágenes eran desconocidas, por lo que de nuevo el croquis viene a abrir nuevas discusiones al respecto.

Por último, el croquis, junto con el expediente que lo alberga, proporciona datos preciosos como el año de su primer uso, el lugar exacto en donde se proyectó el coro, los asientos de las autoridades civiles, la proyección del bautisterio, algunas costumbres funerarias, entre otros datos visibles en el croquis o descritos en las fojas del expediente.

Los archivos todavía conservan valiosos tesoros por descubrir. El croquis de la catedral de Mérida de 1574 es uno de estos casos. Si bien muchas veces se tiene que correr con mucha suerte, también el investigador debe procurar la revisión sistemática, a veces muy cansada, a veces difícil por los tiempos y los recursos, pero necesaria en el oficio para ir rellenando lagunas que muchas veces se pensaban imposibles.

\section{Notas PALEOGRÁficas}

\section{Información dentro del espacio del coro}

El coro del perlado, dignidades, y cantores./ Este padrón se ha hecho para paz común de esta ciudad y solas /las personas que aquí estuvieren sus nombres, tienen y tendrán de /aquí adelante, acción a las sepulturas aquí señaladas, salvo sino /la perdieren por dejarlas de ofrendar, como es uso y costumbre. /Y porque esto tenga más firmeza, manda su señoría so pena de excomunión /mayor, que ha ninguno se les haga agravio, ni le quiten su sepultura, /y encomien- 
da su señoría mucho al señor dean de esta santa iglesia, /y provisor general, los ampare y haga justicia, y así lo pro/veyó y firmó siendo testigos Joan Ramos, vecino de esta ciudad, a quin/ce de octubre de mil y quinientos setenta y cuatro ańos, frater didacus lepiscopus, ante mí, Andrés Mexia, notario. /Silla episcopal/deán.

\section{Información en la parte del bautisterio}

En estas cuatro cua/dras está la se/pultura [roto] a/[roto] baptismo que/llega hasta las dos/[roto] de la cerca de/[roto] dicha iglesia.

\section{Información en la parte inferior del croquis}

Hecho y sacado, corregido y concertado fue este traslado del padrón original, por mí, Francisco de Orozco, notario apostólico, vecino de esta ciudad de Mérida de Yucatán, con/ licencia del reverendísimo señor don fray Diego de Landa, obispo de este obispado de Yucatán, Cozumel, y Tabasco, del consejo de su majestad, para que quede en mi poder, el cual pasó/ su señoría reverendísima su autoridad y decreto judicial, tanto cuanto puede y con derecho debe, para que valga y haga fe aquí e fuera del, e lo mandó sellar de mi/ pedimento con su sello, e se le volvió el original que quedó en su archivo, y fueron presentes por testigos al verlo corregir e concertar con el dicho original/, Francisco Gutiérrez y Alonso Sánchez clérigo, criados de su señoría reverendísima, va sobrerraido la última sepultura que está pegada a la puerta del perdón, /de la mano izquierda, porque por yerro se había puesto en ella la señal de la dicha puerta del perdón, que fecho en la ciudad de Mérida de Yuca/tán a diez e ocho días del dicho mes de octubre de mil y quinientos setenta y cuatro años, el cual hago padrón hasta hoy dicho dia, no parecen asentados el más/ de 33 personas y son dońa Andrea del Castillo, Antonio de Mayorga, Fernando de Castro Polanco, Melchor Pacheco, Juan de Magańa Arro/llo, Diego Álvarez, Joana Suárez, Marcos Rodríguez, Rodrigo Franquez, Nuño de Castro, Francisco Tamayo, Francisco Pacheco, Jerónimo de Castro, la de Cas/tañeda, Fernando de Bracamonte, la de Francisco de Magaña, Luis de Santa Cruz, Cristóbal Sánchez, 
Alonso d Castro, Lucas de Paredes, Gómez de/ Castrillo, Cristóbal de San Martín, Francisco de Arceo, Cristóbal de Rojas, Ana de Campos, Joan López, Nicolás de Aquino, Blas Hernández, Bartolomé Rojo,/ Joan Bote, Jerónimo Pérez, Beatriz López, la viuda de Antón Julián, Diego Hernández de Hoyos, en fe de lo cual hice aquí mi signo, que es a tal/ testimonio de verdad. Francisco de Orozco, notario apostólico, fr.d. eps. Rubrica.

\section{Archivos}

AGN. Archivo General de la Nación

AGI. Archivo General de Indias

APAY. Archivo Parroquial de la Arquidiócesis de Yucatán

\section{BIBLIOGRAFÍA}

Ancona, Eligio. 1978. Historia de Yucatán. Mérida: Ediciones de la Universidad de Yucatán.

Bretos, Miguel. 2013. La catedral de Mérida. La gran casa de Dios en medio de T'ho'. Mérida: Cultura Yucatán A.C.

1991. Iglesias de Yucatán con portafolio fotográfico de Christian H. Rasmussen. Mérida: Dante.

CÁRdenas y VAlencia, Francisco de. 1937. Relación historial eclesiástica de la provincia de Yucatán de la Nueva España, escrita en el año de 1639. México: Antigua Librería Robredo de José Porrúa e hijos.

Carrillo y Ancona, Crescencio. 1979. El obispado de Yucatán. Historia de su fundación y de sus obispos. Primera edición en 1895. 3 tomos. Mérida: Fondo Editorial de Yucatán.

Chuchiak, John. 2006. "El regreso de los autos de fe: fray Diego de Landa y la extirpación de idolatrías en Yucatán”. Peninsula Revista Semestral de la Coordinación de Humanidades 1(0): 29-47.

Elliot, John H. 2010. España, Europa, y el mundo de Ultramar (1500-1800). México: Taurus.

García Bernal, Manuela Cristina. 2005. Economía, politica y sociedad en el Yucatán colonial. Mérida: Universidad Autónoma de Yucatán. 
García Cuadrado, María Dolores. 2000. "San Cristóbal: significado iconológico e iconográfico". Antigüedad y Cristianismo (17): 343-366.

López Cogolludo, Diego. 1688. Historia de Yucatán, Primera edición, ed. Juan García Infanzón. Madrid.

Martínez GiL, Fernando. 1993. Muerte y sociedad en la España de los Austrias. Madrid: Siglo XXI.

Martínez Peláez, Severo. 2012. La patria del criollo. Ensayo de interpretación de la realidad colonial guatemalteca. México: Fondo de Cultura Económica.

Molina Solís, Juan Francisco. 1943. Historia del descubrimiento y conquista de Yucatán. 2 tomos. México: Ediciones Mensaje.

Relaciones Histórico Geográficas de la Gobernación de Yucatán, 2008, 2 tomos, ed. Mercedes de la Garza, Ana Luisa Izquierdo, María del Carmen León y Tolita Figueroa. México: Universidad Nacional Autónoma de México.

Rubio MañÉ, Ignacio. "Los primeros vecinos de la ciudad de Mérida de Yucatán”. Academia Mexicana de la Historia correspondiente de la Real de Madrid, Discurso de recepción del D. J. Ignacio Rubio Mañé, sillón 19, 7 de noviembre de 1943.

Scholes, France V. y Eleanor B. Adams. 1938. Diego de Quijada, alcalde mayor de Yucatán, 1561-1565. Documentos sacados de los archivos de España. México: Antigua Librería Robredo de José Porrúa e hijos.

\section{Documento}

Croquis de la catedral de Mérida, Yucatán, de 1574 


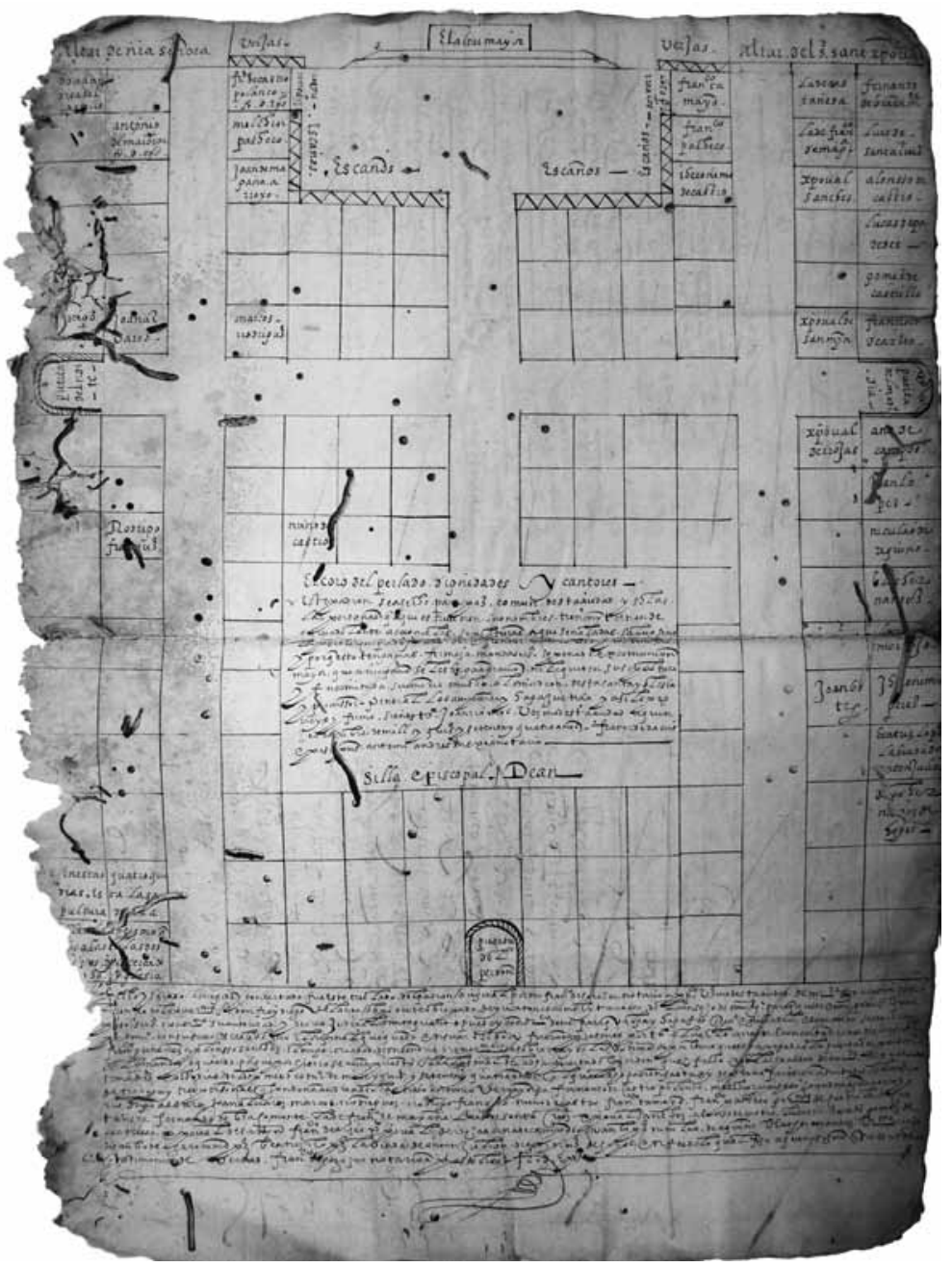

